\title{
PARENTS' PERCEPTIONS, ATTITUDES AND ACCEPTABILITY OF TREATMENT OF CHILDHOOD MALARIA WITH ARTEMISININ COM- BINATION THERAPIES IN GHANA
}

\author{
G. O. ADJEI ${ }^{1}$, A. K. DARKWAH ${ }^{2}$, B. Q. GOKA ${ }^{3}$, C. BART-PLANGE ${ }^{4}$, M. L ALIFRANGIS ${ }^{5}$, J. A. \\ L. KURTZHALS ${ }^{5}$, O. P. RODRIGUES ${ }^{3}$
}

\begin{abstract}
${ }^{1}$ Centre for Tropical Clinical Pharmacology \& Therapeutics and ${ }^{3}$ Department of Child Health, University of Ghana Medical School, Accra, Ghana; ${ }^{2}$ Department of Sociology, University of Ghana, Legon; ${ }^{4}$ National Malaria Control Programme, Ghana Health Service, Accra, Ghana; ${ }^{5}$ Centre for Medical Parasitology, Copenhagen University Hospital, Denmark
\end{abstract}

Corresponding Author: Dr George Obeng Adjei

Email: goadjei@yahoo.com

Conflict of interest: None

\section{SUMMARY}

Background: There is little information on sociocultural and contextual factors that may influence attitudes of patients to new treatments, such as artemisinin combination therapies (ACT).

Methods: Semi-structured questionnaires and focus group discussions were used to assess views of parents of children with uncomplicated malaria treated with ACT in a low socio-economic area in Accra, Ghana.

Results: The majority of parents reported a favourable experience, in terms of perceived i) rapidity of symptom resolution, compared to their previous experience of other therapies for childhood malaria, or ii) when their experience was compared that of parents of children treated with monotherapy. The parents of children treated with ACT were more willing to pay for the treatment, or adhere to the full treatment course. The explanations given for adherence were consistent with conventional biomedical explanations. Although careseeking practices for childhood malaria were considered appropriate, perceived or real barriers to accessible health care were also important factors in the decision to seek treatment. Household dynamics and perceived inequities at the care-provider-patient interface were identified as having potential negative impact on care-seeking practices and adherence.

Conclusions: Health education messages aimed at improving the response to childhood febrile illness should include other strategic stakeholders, such as decisionmakers at the household level. The effectiveness and implementation success of the ACT policy could be enhanced by highlighting and reinforcing messages intrinsic to these regimens. Integrating the views of caretakers during the clinical encounter was validated as an empowerment tool that could aid in the appropriate responses to childhood illness.

Keywords: socio-cultural factors, artemisinin combination therapy, malaria, children, Ghana

\section{INTRODUCTION}

Artemisinin combination therapy (ACT) is the current standard treatment for uncomplicated malaria. The efficacies of currently deployed ACTs have been extensively evaluated in clinical trials employing directly observed treatment and standard methods of assessment. There have been fewer studies that have focused on the more subjective and/or socio-cultural factors or contexts within which such treatments are administered.

Subjective and/or socio-cultural factors could influence important characteristics such as adherence to treatment, an influential characteristic of the overall effectiveness. There is evidence to show that subjective meanings influence how patients integrate treatments with everyday life ${ }^{1}$, or that lay beliefs about medication differs from standard biomedical interpretations. ${ }^{2-5}$

There is also evidence showing that disregarding patients' beliefs could adversely influence adherence to treatment ${ }^{6}$ - an important determinant of the drug effectiveness. The majority of reports on contextual factors influencing malaria treatment apply to chloroquine and antimalarials that are no more used as monotherapy such as sulphadoxine-pyrimethamine. There is scanty information on these factors as they relate to ACTs, which differ in content and in quality from monotherapies, and to which adverse effect perceptions may differ. Gathering information on these characteristics could influence the implementation process and success of the new ACT policy.

In this study, factors along the continuum of careseeking-to treatment-completion have been evaluated during treatment of children with uncomplicated malaria with ACT or monotherapy, and potential underlying factors that may have influenced the reasoning underlying expressed attitudes and perceptions have been explored. 


\section{METHODS}

\section{Study site}

This study was a sub-component of a larger trial that was conducted to generate efficacy and safety data on amodiaquine-artesunate and artemether-lumefantrine, two ACT regimens that were under consideration for possible adoption as first-line therapies for uncomplicated malaria in Ghana at the time this study was conceived. The study was done in two primary health facilities, Korle Bu and Mamprobi polyclinics, facilities that are situated in a densely populated, ethnically diverse, and predominantly low socio-economic part of Accra, Ghana. The majority of residents in the area are low-income earners, who work in the informal sector, mainly as petty traders if female, or artisans or fishermen, if male.

\section{Subjects and methods}

The subjects of the study were parents or primary caregivers of children who participated in a longitudinal efficacy and safety clinical trial (trial registration number NCT $00406146 \mathrm{http}: / / \mathrm{www} . c$ linicaltrials.gov). The full details of the trial have been reported previously elsewhere ${ }^{7}$. Briefly, children with uncomplicated malaria fulfilling inclusion and exclusion criteria of the trial were randomized to treatment with artesunate+amodiaquine, artemether-lumefantrine, or amodiaquine monotherapy and then followed up, initially for 28 days, and then monthly for up to one year. Ethical approval for the study was granted by the Ethical and Protocol Review Committee of the University of Ghana Medical School.

A subset of parents of recruited children from the clinical trial were interviewed on the day after completion of treatment (day 3 ), or on the next follow up day (day 7).

The interviewed parents or caregivers were randomly selected from a computer-generated random numbers scheme. In cases where the selected parent or caregiver declined to participate, the parent of the next consecutively recruited patient was requested to participate. A pre-tested questionnaire originally drafted in English, and translated into Ga and Twi, two main local languages spoken in the study area, was used to interview parents or caregivers. The interviews were conducted by a field worker not involved in clinical management. The questions in the survey were informed by themes related to malaria treatment, but within the broader context and perspective of acute childhood illness. The basic socio-demographic information, as well as questions on the following areas were included in the survey: health seeking behaviour, with emphasis on treatment practice for childhood fever; acceptability of the received treatments, in terms of perceived efficacy, dosage schedule and side effects; attitudes towards adherence and cost of treatment; and perceptions of drugs that are combined.

After the interviews, two focus group discussions (FGDs) were conducted one month apart, with a subgroup of purposively selected parents. Two major criteria that determined inclusion in the FGD were, age of the child and educational level of parent. In each FGD, parents who had no formal education or have completed no more than primary school education as well as those who have completed post-primary education were included. In addition, these parents were selected, based on whether the child was under the age of five or above five years of age. Thus, in effect, each of the FGD's included parents with wide-ranging educational background as well as parents of children under five as well as parents whose children were aged above five years. The two FGD's were both held on Saturdays in a meeting room at the Department of Child Health of the Korle Bu Teaching Hospital. The FGD sessions elaborated on issues relating to health seeking behaviour, beliefs, perceptions and feelings about conventional (allopathic; western type) antimalarial drugs and on herbal treatments for malaria, as well as preferred treatment practices and their determinants. In the FGD, broad areas of consensus, conflict and absences were identified if possible, and identification of converging and diverging discourses, as well as possible changes in perspective was noted, where appropriate.

\section{RESULTS}

\section{Baseline characteristics}

A total of 101 randomly selected parents participated in the questionnaire interview, and 15 subjects participated in the FGD's. The majority of female caregivers had a low educational background compared to their male counterparts. The main occupation of the majority of subjects was petty trading, or other small-scale private business. The baseline demographic characteristics of interviewed subjects are summarized in Table 1.

\section{Attitude to febrile illness}

The majority of respondents $(66.3 \%)$, reported that the child mainly suffered from conditions that could be construed as febrile illness. Of this, $45.5 \%$ reported that the child suffered mainly from 'fever', while $20.8 \%$ reported 'ahohyehye yaree', translated as febrile illnesses. Some respondents (13.9\%) specifically reported that the child mainly suffered from 'malaria'. The drug store was the first point of call for the majority $(70 \%)$ in the event of a febrile illness, and only if the symptoms did not improve after taking the medication received at the drug store would they report to a conventional health facility. 
Table 1 Demographic characteristics of interviewed parent or primary caregiver

\begin{tabular}{|l|l|l|}
\hline \multicolumn{1}{|c|}{ Item } & \multicolumn{1}{|c|}{ Response } & No. (\%) \\
\hline Age of mother or primary female caregiver & $20-29$ & $28(27.7)$ \\
& $30-39$ & $49(48.5)$ \\
& $40-49$ & $16(15.8)$ \\
& $50-59$ & $5(4.9)$ \\
Highest level of formal educational level attained & Nonknown & $3(3.0)$ \\
by mother or primary female caregiver & First cycle (primary) & $18(17.8)$ \\
& Second cycle (secondary) & $67(66.3)$ \\
& Third cycle (tertiary) & $12(11.9)$ \\
\hline Highest level of formal education attained by fa- & None & $4(4.0)$ \\
ther & First cycle (primary) & $5(5.0)$ \\
& Second cycle (secondary) & $41(40.6)$ \\
Occupation of mother or primary female care- & Third cycle (tertiary) & $23(22.8)$ \\
giver & Don't know & $16(15.8)$ \\
& Trader & $14(13.9)$ \\
\hline & Housewife & $65(64.4)$ \\
& Seamstress & $8(7.9)$ \\
& Unemployed & $7(6.9)$ \\
& Teacher & $5(4.9)$ \\
& Hairdresser & $3(3.0)$ \\
& Fishmonger & $3(3.0)$ \\
\hline
\end{tabular}

Artisan includes electrician, $n=5$; auto mechanic, $n=6$; tailor, $n=1$, and welder, $n=2$. Other includes secretary, $n=1$; printer, $n=1$; school proprietor, $n=1$; clearing agent, $n=1$; information technology specialist, $n=1$

A small proportion of respondents said they would "look around the house" $(10.8 \%)$ or "ask the neighbours for some medication" (14.8\%), before resorting to a health facility. Notably, one respondent $(0.9 \%)$ indicated that she would have to "wait for the father of the child to return from work or travel" before taking any decision. The majority of respondents had used acetaminophen (with or without chloroquine) for treating the episode of childhood fever preceding the current episode (Table 2).

A 32 year old female participant in the FGD noted on further exploration of this theme:

"Sometimes, it (the illness) is so critical. When one decides to go to the hospital, one is expected to join a queue for identity card. Thereafter one has to join another queue before seeing the doctor, and therefore continues enduring the "pain". At the drugstore, the situation is different. You get the drug to reduce the "pain" almost as soon as you get there. Once you have gotten some pain relief, you can then afford to visit the hospital".

\section{Perceptions of efficacy: contrast of the present with past treatments}

Approximately $50 \%$ of respondents recalled that it took about three days for the child to recover from the episode of febrile illness immediately preceding the current episode for which they are seeking care. A similar proportion recalled, "itch" as the major adverse event associated with previously received treatments for childhood febrile illness. About a quarter $(23 \%)$ of respondents recalled that, for a previous episode of febrile illness, the child got better within 24 hours, while $70 \%$ recalled that for the current episode, the child got better within 24 hours. Approximately 47\% respondents noted that the current treatment "worked" definitely "quicker" (compared to $4 \%$ who thought otherwise) than the previous treatment $(\mathrm{p}<0.05)$. This response was obtained despite all respondents (except one) thinking there was no difference or difficulties associated with the dosage schedules between the current and the previous treatments for childhood fever. 
Table 2 Perception of child health and response to childhood illness

\begin{tabular}{|c|c|c|}
\hline Item & Response & No. $(\%)$ \\
\hline $\begin{array}{l}\text { What type of illness does your child usually suf- } \\
\text { fers from }\end{array}$ & $\begin{array}{l}\text { 'Fever'/' febrile illnesses' } \\
\text { 'Malaria' } \\
\text { Does not usually get ill } \\
\text { Headaches } \\
\text { Cough } \\
\text { Unknown } \\
\text { Asthmatic attacks }\end{array}$ & $\begin{array}{l}67(66.3) \\
14(13.9) \\
10(9.9) \\
3(3.0) \\
3(3.0) \\
3(3.0) \\
1(1.0)\end{array}$ \\
\hline $\begin{array}{l}\text { How did you respond to the child's fever the last } \\
\text { time }\end{array}$ & $\begin{array}{l}\text { Got a drug from a chemical shop } \\
\text { Went to the clinic } \\
\text { Found some medicine in the house } \\
\text { Took the child to church } \\
\text { Waited for the father to return from work } \\
\text { Not sure }\end{array}$ & $\begin{array}{l}68(67.3) \\
20(19.8) \\
9(8.9) \\
1(1.0) \\
1(1.0) \\
2(2.0) \\
\end{array}$ \\
\hline $\begin{array}{l}\text { What medicine did you give the child the last } \\
\text { time he/she had a febrile illness }\end{array}$ & $\begin{array}{l}\text { Cannot tell } \\
\text { Paracetamol (acetaminophen) } \\
\text { Chloroquine } \\
\text { Chloroquine and paracetamol } \\
\text { \#Others }\end{array}$ & $\begin{array}{l}34(33.6) \\
27(26.7) \\
20(19.8) \\
12(11.8) \\
8(7.9)\end{array}$ \\
\hline $\begin{array}{l}\text { How quickly did the child get well the last time } \\
\text { he/she experienced a febrile illness }\end{array}$ & $\begin{array}{l}\text { Three days later } \\
\text { More than four days later } \\
\text { The next day } \\
\text { Not applicable } \\
\text { Two days later } \\
\text { The same day } \\
\text { Did not recover for some time }\end{array}$ & $\begin{array}{l}25(24.8) \\
23(22.8) \\
16(15.8) \\
11(10.9) \\
9(8.9) \\
7(6.9) \\
2(2.0)\end{array}$ \\
\hline $\begin{array}{l}\text { Would you prefer a drug combination or a regi- } \\
\text { men consisting of a single drug for treating your } \\
\text { child's malaria }\end{array}$ & $\begin{array}{l}\text { Combined } \\
\text { Single } \\
\text { It depends } \\
\text { Do not know }\end{array}$ & $\begin{array}{l}58(57.4) \\
33(32.7) \\
6(5.9) \\
4(3.9) \\
\end{array}$ \\
\hline $\begin{array}{l}* \text { Why would you prefer a combined or single } \\
\text { drug }(\mathrm{n}=58)\end{array}$ & $\begin{array}{l}\text { Two drugs combined are better than one } \\
\text { Two drugs will work better and faster } \\
\text { Combined therapy is more convenient } \\
\text { Cannot explain }\end{array}$ & $\begin{array}{l}17(29.3) \\
27(46.5) \\
8(13.7) \\
6(10.3)\end{array}$ \\
\hline $\begin{array}{l}\text { Is it important to give the full 3-day course of } \\
\text { treatment, even if the child recovers earlier }\end{array}$ & $\begin{array}{l}\text { Yes } \\
\text { No } \\
\text { Cannot tell } \\
\end{array}$ & $\begin{array}{l}87(86.1) \\
13(12.9) \\
1(1.0) \\
\end{array}$ \\
\hline $\begin{array}{l}\text { Why is it important to administer the full three } \\
\text { day course of treatment, even when your child } \\
\text { recovers earlier }\end{array}$ & $\begin{array}{l}\text { To be able to cure the disease completely } \\
\text { To make sure that I follow the doctor's instruction } \\
\text { To be able to prevent the illness from returning } \\
\text { In order not to waste the medicine } \\
\text { Cannot tell }\end{array}$ & $\begin{array}{l}33(32.7) \\
31(30.7) \\
12(11.9) \\
8(7.9) \\
17(16.8)\end{array}$ \\
\hline
\end{tabular}

\#Other includes "teething mixture", n=2; "masada", "teeda”, “top-fever", "antibiotic", "alagbin”, "antihelminthic" (all $\mathrm{n}=1$ ). *Refers only to those who said they preferred combined therapy

This theme was elaborated in the FGD, where a 28 year old female participant noted:

"This medicine has worked miracles for me".

Another participant in the FGD, a 35 year old caretaker narrated:
"My child was seriously ill. He could not even eat. He only took water. I was really afraid. For the second day (of treatment), it was my husband who sent him to the hospital. After coming back, the child came to me and complained that he was hungry. I became happy. I found him something (to eat). He even complained after eating that he wanted more. I was really happy for him. 
I then believed that the drug he was given was good for him. I gave some of the drug to my three younger children and they are all well. The doctors really did well. They are wonderful. The child was seriously ill but just a day after, he felt okay".

\section{Differences in perception of efficacy between the current treatments}

There was no difference in perception of the rate of recovery between respondents whose children received amodiaquine+artesunate and those whose children received artemether-lumefantrine. There was a trend, though not significant $(\mathrm{p}=0.09)$, towards a perception of quicker recovery; however, when subjects whose children were treated with ACT was compared to those whose children received amodiaquine monotherapy.

\section{Acceptability}

The proportion of respondents who expressed a preference for a drug combination (57.4\%), was higher $(p<0.05)$ than those who expressed preference for a single drug (32.7\%). Common reasons given for the hypothetical preferences were, "a combination of drugs should work better and faster" $(46.6 \%)$ or "two or more drugs should be better than one drug" $(29.3 \%)$. The rest of respondents who indicated a preference for a drug combination could not express the reason(s) for that preference.

\section{Willingness to pay for treatments}

A majority $(66.3 \%)$ of respondents indicated in the questionnaire survey that - provided the child recovered quickly enough - the cost of the drug was not the primary factor that would determine their willingness to pay for the drugs. However, during the FGD, it was agreed that, most participants would be able to afford, or would be willing to pay not more than two Ghana cedis (approximately US\$2.20) for the received treatments. It was not possible to make a comparison on the willingness or ability to pay for the treatments across socio-economic groups, partly because the majority of respondents were of low socio-economic status and also because the study was not primarily designed to differentiate between, or detect differences between socio-economic groups.

\section{Adherence to treatment}

The majority of respondents $(86.1 \%)$ considered it important to complete the full treatment course. By comparison, a smaller proportion $(12.9 \%)$ indicated they would stop the medication if their ward appeared to have recovered before completing the full three-day treatment course. The reasons cited for these preferences were consistent with conventional biomedical interpretations, as elaborated in the FGD, in which a 38 year old male participant noted:
"It is important to complete the full course of treatment because if the doctor says you should, then you simply should".

Another participant in the FGD, a 34 year old female caretaker narrated:

"I will do what the doctor asks me to do. If he advises that I take the drug for a week, I will do so. If I do not, it (the illness) can come back. But if I complete the medication schedule, I can feel confident to go to the doctor, even if the disease comes back".

However, for a significant proportion of respondents $(n=31 ; 30.7 \%)$, the reason for completion of the full treatment course was "to comply with the instructions of the prescribing physician”.

\section{DISCUSSION}

This study was conducted to gain some insight into subjective reasons underlying perceptions and attitudes accompanying the use of ACT for treating childhood malaria in Ghana. The finding that caregivers preferred to visit the chemical shop as the first point of call in the event of childhood fever is consistent with several reports, which have generally concluded that, majority treatment of childhood malaria occurs outside the public health system. ${ }^{8-10}$ This practice is also consistent with several studies concluding that, mothers can treat childhood malarial fever at home ${ }^{11}$ - a practice that has been associated with a reduction in allcause childhood mortality. ${ }^{12}$ several generic strategies such as, eliminating or reducing the barriers to formal health care access, scaling up the Home-based Malaria Management Strategy, improving health care services in the private sector, as well as facilitating the referral system are all means that could lead to improvement in the response to childhood febrile illness in Ghana.

The response of the single caregiver indicating she would wait for the father of the child to return from work or travel before seeking care is of concern, since similar attitudes have recently been reported from two (rural) communities in Ghana ${ }^{13}$, where mothers or female caregivers who lacked economic support, or who disagreed with husbands or family elders faced difficulties accessing care for their children. Although economic and geographical barriers are important determinants of health care seeking behaviour ${ }^{14}$, equally influential are contextual factors and socio-cultural dynamics. ${ }^{15,16}$ The obvious implication of this lone but important response is that removing, or reducing outof-pocket payments for health care at the point of access, together with reform of the administrative and socio-political milieu within which premium based systems for health care financing operate, as being currently introduced within the National Health Insurance 
Scheme (NHIS), are important means of addressing some of these barriers. There should be further research on issues such as, effect of gender, traditional family structures and dynamics of the decision-making process (es) within the NHIS.

The hypothetical preference of respondents for ACT, as these regimens were perceived as 'stronger' was of interest: Across Africa in general, allopathic medicines are considered 'strong' or 'powerful'; therefore, combining these 'powerful' substances could only make them 'stronger'. For this reason, labelling ACT as "strong therapy", by virtue of its composite nature could be considered a "culturally compelling message", because, this concept shifts focus from cognitive antecedents to action ${ }^{17}$, and could therefore be a potentially useful message that could facilitate acceptability of ACT in Ghana.

There was a discrepancy between responses suggesting a minimal influence of the cost of drugs on what amount parents or caregivers were willing to pay, as expressed in the survey, and expressed opinions that placed clear limits on how much participants were willing to pay, as elicited in the FGD's. The difference could be due to the short time that elapsed between recovery from the illness, and the time the questionnaire interview was conducted, when elation over the child's recovery was fresh in the memory of parents.

After a child has just recovered from an acute bout of malaria, it is more likely for the mother or caregiver to express a willingness to pay more than they could realistically afford. However, after several weeks, the elation over the recovery from the illness may have diminished, and could have allowed for a more sober reflection and a more realistic appraisal of financial ability. The responses in the FGD could therefore be a truer reflection of the willingness or ability to pay for such treatments. However, all drugs were provided free, therefore parents were not under undue pressure to make any payments at any time. It is possible then that real reasons for these assertions could be based on more complex interaction of factors, and further research on these issues is warranted.

Furthermore, it has been shown in other studies that, even in the context of poverty, economic considerations are not the primary or sole reason for health care seeking, and that mothers were willing to pay a nominal price for care, provided they received satisfactory care. Other studies have also shown that, anticipated cost of treatment is not a necessarily a dissuading factor in the decision to seek treatment for a sick child. ${ }^{16}$ Thus, overemphasis on economic factors as the cause of inability or unwillingness to seek care for childhood febrile illness or malaria may divert attention from other important factors. On the other hand, new health interventions have the potential to increase inequities in health, as these new interventions are more likely to reach people of higher socio-economic status.

Artesunate+amodiaquine as first-line treatment for uncomplicated malaria was introduced shortly before introduction of the NHIS in Ghana. The implementation process overlapped somewhat in time with the implementation of the NHIS. The introduction of two strategies that have the potential to differentially influence equity to health care access could be considered a "double benefit", as it has a potential diminishing effect on this so-called inverse equity hypothesis. Within the specific context of the themes discussed in this study, participants' preparedness to pay an amount higher than the cost price of artesunate+amodiaquine in public health facilities could be a partial reflection of this hypothesis.

It is reassuring that the majority of respondents made a link between adherence to treatment, treatment completion and its relationship to cure or relapse. This viewpoint is consistent with the conclusions from previous studies showing that, use of efficacious antimalarial drugs are associated with higher adherence rates than less efficacious ones. ${ }^{18}$ It is of concern however, that a significant proportion of respondents were willing to complete the treatment just to be compliant with the instructions of the doctor.

This phenomenon, which has also been reported from the United Kingdom ${ }^{19}$ and from another area in Ghana $^{20}$, may either reflect classical patient-doctor trust, or a broader inequity in social interaction. It is known that provision of accurate verbal instruction by health providers improves adherence, irrespective of socio-economic or educational status ${ }^{21}$, and human communication in general, draws on interpretative schemes and meanings that are deeply ingrained in social structures. ${ }^{22}$ During the interaction between doctor and patient, especially within a clinical encounter, this iterative may be prone to the conveyance of messages of different social positions ${ }^{23,24}$, a situation that could reinforce existing hierarchical or patronizing structures, with the potential of undermining the patient's autonomy for independent action. ${ }^{25}$

Another finding of note, that, leftover antimalarials are kept for anticipated future episodes is not unique to this study, as it has been previously reported from Ghana. ${ }^{26}$ This practice is likely to occur more frequently with ACT treatment, as patients are more likely to recover quicker and therefore less motivated to complete the full course of treatment. However, this could be an 
incidental finding, as it has been shown that effective and well tolerated antimalarials are also associated with high levels of adherence. ${ }^{18}$

\section{CONCLUSION}

ACT was regarded as efficacious by parents of Ghanaian children treated with these regimens for uncomplicated malaria. The responses elicited from most caregivers to childhood febrile illness in this study were appropriate; however, health education messages aimed at improving caregiver response to childhood febrile illness should also target non-female family members and address important issues such as enrolling in schemes that do not require out-of-pocket payments at points of care.

Furthermore, approaches that redefine traditional barriers of communication at the health care providerpatient interface, and which empowers primary care givers to respond appropriately to childhood illness should be explored. However, there could be major differences in perceived side effects of antimalarial treatment between adults and children, therefore, similar studies should be conducted in adults to complement the current study in Ghana.

\section{REFERENCES}

1. Green J, Britten N. Qualitative research and evidence based medicine. BMJ. 1998 Apr 18;316(7139):1230-2.

2. Conrad P. The meaning of medications: another look at compliance. Soc Sci Med. 1985;20(1):2937.

3. Donovan JL, Blake DR. Patient non-compliance: deviance or reasoned decision-making? Soc Sci Med. 1992 Mar;34(5):507-13.

4. Jones DR. Drugs and prescribing: what the patient thinks. J R Coll Gen Pract. 1979 Jul;29(204):4179.

5. Verbeek-Heida PM. How patients look at drug therapy: consequences for therapy negotiations in medical consultations. Fam Pract. 1993 Sep;10(3):326-9.

6. Marinker M. Personal paper: writing prescriptions is easy. BMJ. 1997 Mar 8;314(7082):747-8.

7. Adjei GO, Kurtzhals JA, Rodrigues OP, Alifrangis M, Hoegberg LC, Kitcher ED, et al. Amodiaquineartesunate vs artemether-lumefantrine for uncomplicated malaria in Ghanaian children: a randomized efficacy and safety trial with one year followup. Malar J. 2008;7:127.

8. Agyepong IA. Malaria: ethnomedical perceptions and practice in an Adangbe farming community and implications for control. Soc Sci Med. 1992 Jul;35(2):131-7.

9. Agyepong IA, Kangeya-Kayonda J. Providing practical estimates of malaria burden for health planners in resource-poor countries. Am J Trop Med Hyg. 2004 Aug;71(2 Suppl):162-7.

10. Kengeya-Kayondo JF, Seeley JA, Kajura-Bajenja E, Kabunga E, Mubiru E, Sembajja F, et al. Recognition, treatment seeking behaviour and perception of cause of malaria among rural women in Uganda. Acta Trop. 1994 Dec;58(3-4):267-73.

11. Sirima SB, Konate A, Tiono AB, Convelbo N, Cousens S, Pagnoni F. Early treatment of childhood fevers with pre-packaged antimalarial drugs in the home reduces severe malaria morbidity in Burkina Faso. Trop Med Int Health. 2003 Feb;8(2):133-9.

12. Kidane G, Morrow RH. Teaching mothers to provide home treatment of malaria in Tigray, Ethiopia: a randomised trial. Lancet. 2000 Aug 12;356(9229):550-5.

13. Tolhurst R, Nyonator FK. Looking within the household: gender roles and responses to malaria in Ghana. Trans $R$ Soc Trop Med Hyg. 2006 Apr;100(4):321-6.

14. Ahorlu CK, Koram KA, Ahorlu C, de Savigny D, Weiss MG. Socio-cultural determinants of treatment delay for childhood malaria in southern Ghana. Trop Med Int Health. 2006 Jul;11(7):102231.

15. Ahorlu CK, Koram KA, Ahorlu C, de Savigny D, Weiss MG. Community concepts of malariarelated illness with and without convulsions in southern Ghana. Malar J. 2005;4:47.

16. Kamat VR. "I thought it was only ordinary fever!" cultural knowledge and the micropolitics of therapy seeking for childhood febrile illness in Tanzania. Soc Sci Med. 2006 Jun;62(12):2945-59.

17. Panter-Brick C, Clarke SE, Lomas H, Pinder M, Lindsay SW. Culturally compelling strategies for behaviour change: a social ecology model and case study in malaria prevention. Soc Sci Med. 2006 Jun;62(11):2810-25.

18. Yeung S, White NJ. How do patients use antimalarial drugs? A review of the evidence. Trop Med Int Health. 2005 Feb;10(2):121-38.

19. Britten N. Patients' ideas about medicines: a qualitative study in a general practice population. $\mathrm{Br} J$ Gen Pract. 1994 Oct;44(387):465-8.

20. Agyepong IA, Ansah E, Gyapong M, Adjei S, Barnish G, Evans D. Strategies to improve adherence to recommended chloroquine treatment regimes: a quasi-experiment in the context of integrated primary health care delivery in Ghana. Soc Sci Med. 2002 Dec;55(12):2215-26. 
21. Kachur SP, Khatib RA, Kaizer E, Fox SS, Abdulla SM, Bloland PB. Adherence to antimalarial combination therapy with sulfadoxine-pyrimethamine and artesunate in rural Tanzania. Am J Trop Med Hyg. 2004 Dec;71(6):715-22.

22. Byrne E, Gregory J. Co-constructing local meanings for child health indicators in communitybased information systems: the UThukela District Child Survival Project in KwaZulu-Natal. Int $J$ Med Inform. 2007 Jun;76 Suppl 1:S78-88.

23. Waitzkin H. Doctor-patient communication. Clinical implications of social scientific research. JAMA. 1984 Nov 2;252(17):2441-6.

24. Waitzkin H. The micropolitics of medicine: a contextual analysis. Int $J$ Health Serv. 1984;14(3):339-78.
25. Montgomery CM, Mwengee W, Kong'ong'o M, Pool R. 'To help them is to educate them': power and pedagogy in the prevention and treatment of malaria in Tanzania. Trop Med Int Health. 2006 Nov;11(11):1661-9.

26. Yeboah-Antwi K, Gyapong JO, Asare IK, Barnish G, Evans DB, Adjei S. Impact of prepackaging antimalarial drugs on cost to patients and compliance with treatment. Bull World Health Organ. 2001;79(5):394-9. 